AS TECNOLOGIAS DE INFORMAÇÃO E COMUNICAÇÃO

NA FORMAÇÃO INICIAL DE PROFESSORES DO 1 CICLO DO ENSINO BÁSICO FATORES CONSTRANGEDORES INVOCADOS PELOS FORMADORES PARA O USO DAS TECNOLOGIAS

\author{
FONSECA, Maria Gorete Ramos (Portugal, Lisboa) ${ }^{1 *}$ \\ ${ }^{1}$ Instituto de Educação da Universidade de Lisboa \\ ORCID ID: https://orcid.org/0000-0001-5652-416X
}

\begin{abstract}
RESUMO
O artigo tem como objetivo apresentar e discutir, a partir das representações dos formadores de professores, os fatores que atuam como barreira ao uso e promoção das tecnologias de informação e comunicação na preparação profissional dos futuros professores para o uso pedagógico dessas tecnologias. É um estudo descritivo interpretativo, centrado nos formadores de duas instituições públicas de ensino superior em Portugal que formam professores do $1^{\circ}$ ciclo do ensino básico. Para atender ao objetivo, realizadaram-se 20 entrevistas semidiretivas. Para além dos constrangimentos invocados no âmbito do currículo de formação, as evidências apontam para a dificuldade de os futuros professores passarem pela experiência de observar e experimentar exemplos de uso pedagógico das tecnologias de informação e comunicação devido, em grande parte, ao déficit de conhecimentos/formação dos próprios formadores na área e às representações que detêm sobre o ensino e as tecnologias de informação e comunicação, que tendem a influenciar o modo como os futuros professores as utilizam.
\end{abstract}

PALAVRAS-CHAVE

Formadores de professores do $1^{\circ}$ CEB. Formação inicial de professores. TIC Fatores constrangedores. Representações sobre as TIC.

\title{
THE INFORMATION AND COMMUNICATION TECHNOLOGIES IN THE
}

\section{INITIAL TRAINING OF K-12 TEACHERS - CONSTRAINING FACTORS FOR THE USE OF TECHNOLOGIES INVOCATE BY TRAINERS}

\begin{abstract}
The article aims to present and discuss, from the representations of teacher trainers, the factors that act as a barrier to the use and promotion of information technologies and communication technologies (ICT) in professional preparation of future teachers for the pedagogical use of ICT. It is an interpretative descriptive study focused on trainers of two public universities in Portugal that train K-12 teachers. Twenty semi-directional interviews were carried out to meet the objective. In addition to the invoked constraints at the training curriculum level, the evidence points to the difficulty for future teachers to experience and observe examples of pedagogical use of ICTs, due in large part to the lack of knowledge / training of the trainers themselves in the area and their own
\end{abstract}

Educação \& Formação, Fortaleza, v. 4, n. 11, p. 3-23 maio/ago. 2019

DOI: https://doi.org/10.25053/redufor.v4i11.254

http://seer.uece.br/redufor 
representations on teaching and ICT that tend to influence how future teachers use them.

\title{
KEYWORDS
}

K-12 teacher trainers. Initial teacher training. ICT - Constraining Factors. Representations on ICT.

\section{LAS TECNOLOGÍAS DE INFORMACIÓN Y COMUNICACIÓN EN LA FORMACIÓN INICIAL DE PROFESORES DE EDUCACIÓN PRIMARIA - FACTORES CONSTRANGEDORES INVOCADOS POR LOS FORMADORES PARA EL USO DE LAS TECNOLOGÍAS}

\begin{abstract}
RESUMEN
El artículo tiene como objetivo presentar y discutir, a partir de las representaciones de los formadores de profesores, los factores que actúan como barrera al uso y promoción de las tecnologías de información comunicación en la preparación profesional de los futuros profesores para el uso pedagógico de esas tecnologías. Es un estudio descriptivo interpretativo que se centró en los formadores de dos instituciones públicas de educación superior en Portugal de formación de profesores de la educación primaria. Para alcanzar el objetivo, se realizaron 20 entrevistas semidirigidas. Además de las limitaciones invocadas al nivel del currículo de formación, las evidencias apuntan a la dificultad de los futuros profesores en pasar por la experiencia de observar y experimentar ejemplos de uso pedagógico de las tecnologías de información comunicación debido, en gran parte, al déficit de conocimientos/formación de los propios formadores en el área y las representaciones que tienen sobre la enseñanza y las tecnologías de información comunicación que tienden a influir en la forma en que los futuros profesores las utilizan.
\end{abstract}

\section{PALABRAS CLAVE}

Formadores de profesores de la educación primaria. Formación inicial de profesores. TIC - Factores limitadores. Representaciones sobre las TIC.

\section{INTRODUÇÃO}

Numa época em que as tecnologias de informação e comunicação (TIC) têm presença omnipresente na sociedade em geral e consequentemente no espaço escolar, vários são os argumentos que têm justificado a sua integração na escola e, por conseguinte, no processo de ensino e de aprendizagem. Dos professores espera-se que estejam motivados e aptos para usar os diferentes recursos tecnológicos como suporte à sua prática pedagógica, de modo a potenciar as aprendizagens dos alunos. Contudo, apesar do discurso incentivador dos diferentes estudos que têm pugnado pela introdução

Educação \& Formação, Fortaleza, v. 4, n. 11, p. 3-23 maio/ago. 2019

DOI: https://doi.org/10.25053/redufor.v4i11.254

http://seer.uece.br/redufor 
das TIC na educação, dos sucessivos normativos e do discurso político, a grande maioria dos professores, mesmo os recentemente formados, não integra as TIC na sua prática letiva como recurso potenciador de aprendizagens significativas. As questões impõem-se: o que afasta os professores do uso das TIC? O que dificulta o seu uso pedagógico? O que se fez no plano curricular, nas instituições de formação, para incluir as TIC na prática dos professores? O que pensam e fazem os formadores de professores?

Sabemos da importância que os professores atribuem, na sua preparação profissional, à observação dos seus professores e, ainda que possa constituir uma barreira à aprendizagem de novas ideias e de novas práticas, não podemos negligenciar a velha máxima ensinamos como fomos ensinados (MESQUITA; FORMOSINHO; MACHADO, 2012; MIRANDA, 2007). De igual modo, não podemos esquecer que, mesmo antes de exercer a função de professor, o futuro professor já vivenciou informalmente experiências diversificadas como aluno, das quais resultou a construção de uma teoria sobre o que é o ensino, sobre os papéis do professor e sobre ensinar (TARDIF, 2011). Esse saber herdado da experiência escolar é muito forte e muitas das vezes é reativado na formação inicial. Nem sempre a formação consegue contribuir para mudar as crenças formadas (TARDIF, 2011), nomeadamente no que se refere ao uso pedagógico das TIC. Queremos, com isto, relembrar que há uma tendência dos professores para reproduzir, na sua forma de ensinar, o modo como foram iniciados nas suas práticas.

É certo que a formação pode surgir tanto como um fator de incentivo como de obstáculo à introdução das TIC na prática letiva, mas não é suficiente ensinar os futuros professores a usar os diferentes recursos tecnológicos (COSTA, 2008; COUTINHO, 2009; ENOCHSSON; RIZZA, 2009; MIRANDA, 2007). É necessário que as instituições de formação criem oportunidades para que os futuros professores possam experimentar diferentes tecnologias em situações concretas de ensino e de aprendizagem. Não esqueçamos que usar as tecnologias no desenvolvimento da prática depende muito do nível de confiança, de domínio e de conhecimento sobre a influência que as TIC representam no processo de ensino e de aprendizagem que cada formador possui e que a literatura demonstra ser insuficiente (CORONADO, 2013; COSTA et al., 2008; ENOCHSSON; RIZZA, 2009; MIRANDA, 2010). Importa, assim, considerar que novas exigências de papéis e funções, hoje atribuídos aos professores, no caso da vertente do uso pedagógico das TIC no processo de ensino, carecem de 
atenção específica por parte daqueles a quem se imputa a competência de formar os futuros professores.

Ao compararmos os resultados de vários estudos, emerge neles uma nota persistentemente comum: ainda que se constate uma predisposição discursivamente favorável nos professores para a utilização das TIC e as escolas possuam equipamentos tecnologicamente cada vez mais sofisticados, os níveis de utilização pedagógica continuam inferiores em face do expectável (COSTA et al., 2008; ENOCHSSON; RIZZA, 2009; MIRANDA, 2007; MIRANDA, 2010). A discrepância entre os investimentos feitos em equipamentos - e mesmo em formação dos professores - e os resultados verificados no contexto da sala de aula, mostrados por quase todos os trabalhos visitados, destacam o frágil uso das TIC e mais ainda a fraca inovação pedagógica que se esperava que acontecesse.

Como causas prováveis, os estudos vão evidenciando que muitos dos professores que concluem a sua formação inicial acabam por sair com uma preparação desadequada e/ou insuficiente no que se refere ao domínio, exploração e uso do potencial das tecnologias na aprendizagem dos alunos. Salientam que os futuros professores têm dificuldade em observar e em experimentar exemplos de práticas de uso das tecnologias durante a sua formação, nomeadamente no contexto da prática de ensino supervisionada (PES), para poder aprender com os colegas e sobretudo com os professores experientes, nomeadamente os professores supervisores e cooperantes que os acompanham e orientam no estágio, condicionando, em grande parte, a sua utilização futura (COSTA, 2008; COSTA et al., 2008; ENOCHSSON; RIZZA, 2009).

A falta de professores cooperantes que reúnam as qualificações desejadas, com enfoque na atitude e confiança que estes possuem sobre a utilização das tecnologias no ensino, é igualmente assumida por Enochsson e Rizza (2009) como obstáculo na formação para o uso reflexivo e pedagógico das tecnologias pelos futuros professores. A investigação destaca ainda como fatores intrínsecos, que influenciam o modo como os futuros professores utilizam as TIC, as crenças e atitudes que os próprios formadores têm sobre as potencialidades das tecnologias, assim como os níveis de formação preocupantes que detêm no domínio das TIC (CORONADO, 2013; ESTÉVEZNENNINGER et al., 2014; MIRANDA, 2010; SOLIS, 2015). Sabemos que parte do sucesso numa formação de qualidade dos futuros professores para a utilização das TIC 
passa inevitavelmente, para além de outros fatores, pelos objetivos e natureza da formação, pelas crenças e ainda pela exposição dos futuros professores a modelos de prática que criem níveis de confiança, de domínio e de conhecimento sobre a influência que as TIC representam no processo de ensino e na aprendizagem dos alunos (ENOCHSSON; RIZZA, 2009; MIRANDA, 2007; PERALTA; COSTA, 2007).

Contudo, a ausência de formadores que criem condições de observação, em sala de aula, de exemplos convincentes de utilização das TIC disponíveis ou que mostrem eles próprios concretizações motivadoras dessa utilização não pode ser descartada como fator, se não determinante, pelo menos favorável ao uso pedagógico das tecnologias no contexto de ensino e de aprendizagem. Acresce que, no caso concreto da formação de professores para o uso pedagógico das tecnologias, os trabalhos e experiências existentes em Portugal (COSTA, 2008; COSTA et al., 2008; PONTE, 2006; PONTE; SERRAZINA, 1998, entre outros) reportam-se majoritariamente ao conteúdo que os professores devem aprender, tendo havido, até ao momento, pouca preocupação em explorar o papel que os formadores de professores têm na formação adquirida e na prática profissional induzida dos futuros professores no que toca ao uso pedagógico das TIC.

O que atrás fica dito levou-nos a lançar um olhar sobre as representações dos formadores de professores pela influência isomórfica que teoricamente têm quanto ao entendimento da utilização pedagógica das tecnologias no processo de ensino e de aprendizagem, na profissionalização dos futuros professores, focando-nos, em particular, no quadro da formação inicial de professores do 1ำ ciclo do ensino básico (CEB).

\section{DECISÕES METODOLÓGICAS - PROCEDIMENTOS E INSTRUMENTOS}

Inserindo-se num campo de objetivos mais vastos, a investigação de que se faz relato pretendeu conhecer e compreender, através das representações dos atores que intervêm diretamente no campo de estudo, os constrangimentos sentidos na preparação profissional dos futuros professores do $1^{\circ}$ CEB para o uso das TIC no processo de ensino e de aprendizagem.

É um estudo descritivo interpretativo, como mais à frente se dará conta, segue uma metodologia predominantemente qualitativa e centra-se nos formadores de duas

Educação \& Formação, Fortaleza, v. 4, n. 11, p. 3-23 maio/ago. 2019

DOI: https://doi.org/10.25053/redufor.v4i11.254

http://seer.uece.br/redufor 
instituições públicas portuguesas de ensino superior que formam professores. Selecionadas as instituições, foram considerados os docentes que desempenhavam papéis relevantes para os objetivos do estudo. Importa clarificar que se entende por formadores de professores um conjunto alargado de atores que, no quadro das instituições de formação inicial de professores, são responsáveis por definir, aprovar e desenvolver um currículo que prepare os seus estudantes para o exercício da docência. Tendo em conta essa diversidade de atores, cingimo-nos à população que, direta ou indiretamente, participa no processo de formação dos futuros professores (Diagrama 1).

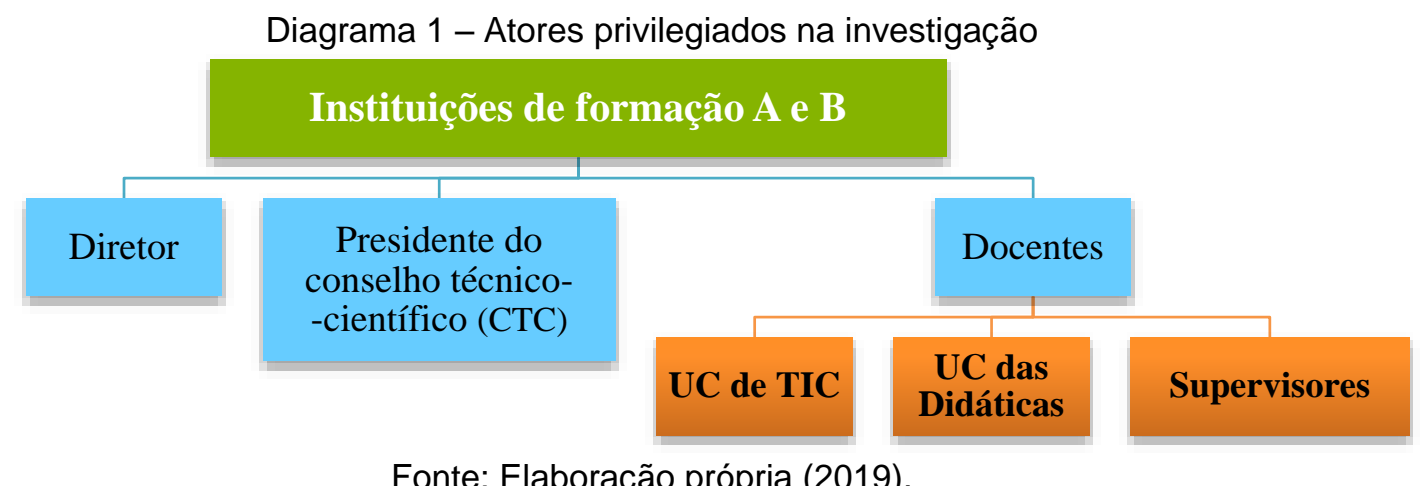

Fonte: Elaboração própria (2019).

Tomados todos os procedimentos, foram ouvidos os diretores das instituições de formação, os presidentes dos conselhos técnico-científicos (CTC), os docentes que asseguram as unidades curriculares (UC) que dizem respeito às TIC como disciplina, os que lecionam as UC referentes às didáticas (português, matemática, estudo do meio e/ou ciências, expressões) e os docentes que asseguram a supervisão da PES/estágio, totalizando nove formadores entrevistados na instituição A e onze na B. Em alguns casos, o mesmo docente executava/acumulava diferentes papéis. À medida que foram sendo ouvidos, cada um referiu o docente da sua instituição que, reconhecidamente por este, lecionava usando as TIC de modo a podermos identificar o conjunto de docentes que as utiliza no desenvolvimento da sua prática.

Recorreu-se a entrevistas semidiretivas como técnica para inquirir os atores, que, depois de gravadas, foram sujeitas a uma análise de conteúdo temática obedecendo aos procedimentos sustentados por Amado (2013) e Bardin (2002). O estudo apresentado é um recorte de uma investigação mais alargada que envolveu a auscultação de outros atores - professores cooperantes e futuros professores que se encontravam a finalizar a sua formação académica -, que pode ser consultada em Fonseca (2018).

Educação \& Formação, Fortaleza, v. 4, n. 11, p. 3-23 maio/ago. 2019

DOI: https://doi.org/10.25053/redufor.v4i11.254

http://seer.uece.br/redufor 
No ponto seguinte é feita a presentação e discussão dos dados das entrevistas referentes aos fatores que, na opinião dos entrevistados, dificultam o uso e promoção das TIC na formação dos futuros professores para o uso pedagógico das TIC no ensino e na aprendizagem.

\section{RESULTADOS E SUA DISCUSSÃO}

Do discurso dos entrevistados, para além de emergirem aqueles que parecem ser os constrangimentos invocados para o uso das TIC no contexto da formação inicial, as declarações põem em evidência igualmente limitações/dificuldades sentidas no uso das TIC, mas na esfera do ensino dos alunos do ensino básico pelos futuros professores. Para uma melhor compreensão, o diagrama seguinte sintetiza os fatores constrangedores emergentes (Diagrama 2).

Diagrama 2 - Constrangimentos invocados pelos formadores das instituições A e B para o uso das TIC

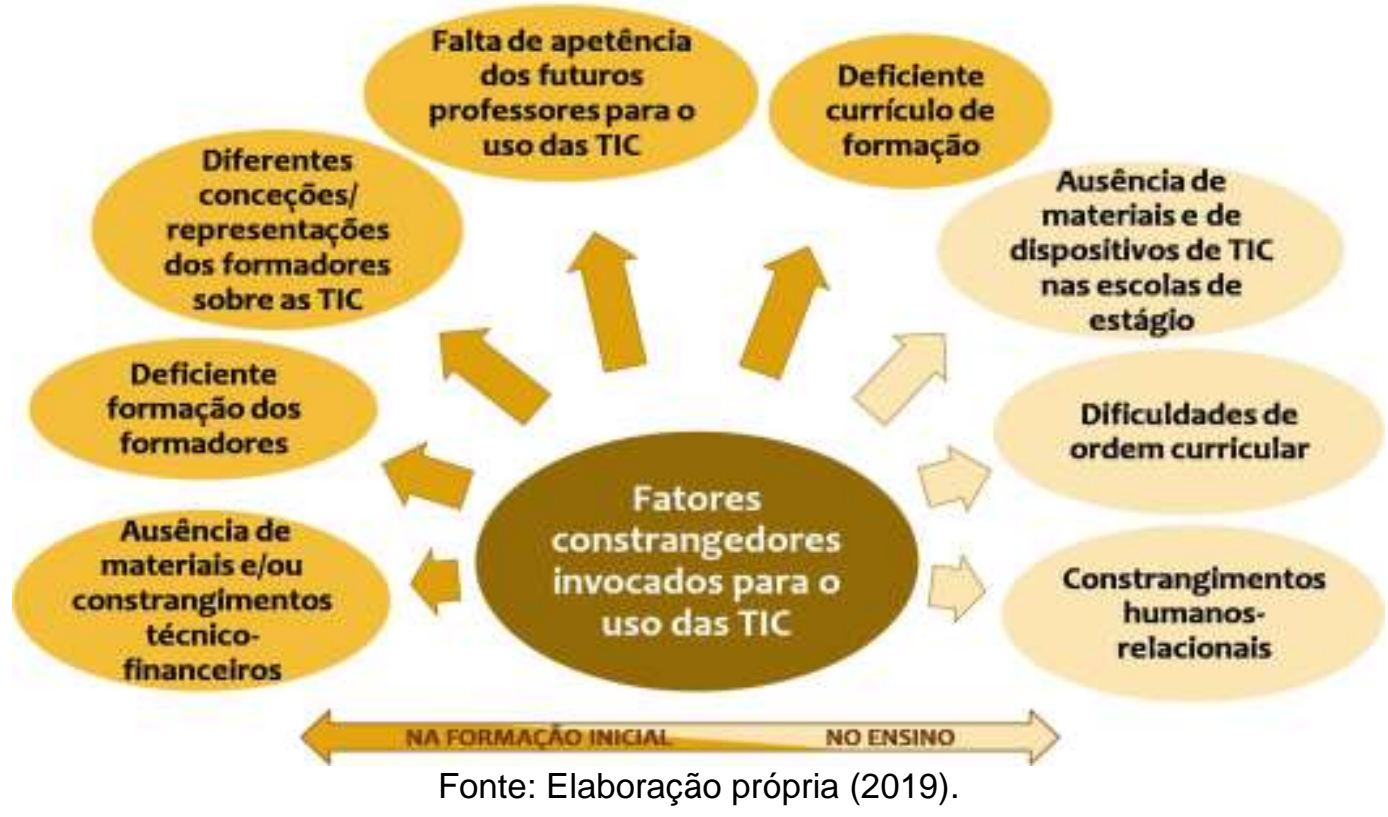

O quadro que se segue permite-nos visualizar o peso discursivo de cada um dos fatores constrangedores emergentes por categoria de entrevistado e em percentagem. Encontra-se organizado por tema, subtema e categorias de conteúdo, evidenciando-se a cinza a percentagem da frequência de unidades de enumeração, de modo a visualizar a percentagem de convergência de opinião entre entrevistados.

Educação \& Formação, Fortaleza, v. 4, n. 11, p. 3-23 maio/ago. 2019 
Quadro 1 - Constrangimentos invocados pelos formadores para o uso das TIC (em percentagem)

\begin{tabular}{|c|c|c|c|c|c|c|c|c|}
\hline \multirow[b]{2}{*}{ 疍 } & & \multirow[b]{2}{*}{ Categorias } & \multicolumn{6}{|c|}{ Entrevistados } \\
\hline & & & 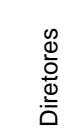 & 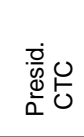 & 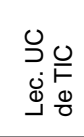 & 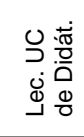 & 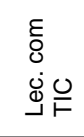 & 这离 \\
\hline \multirow{8}{*}{ 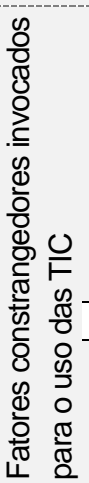 } & & $\begin{array}{l}\text { Ausência de materiais e/ou constrangimentos técnico- } \\
\text {-financeiros }\end{array}$ & 50 & 50 & 75 & 87,5 & 80 & 75 \\
\hline & $\bar{\sigma}$ & Deficiente formação dos formadores em TIC & 50 & 100 & 100 & 75 & 90 & 100 \\
\hline & & $\begin{array}{l}\text { Diferentes concepões/representações dos formadores } \\
\text { sobre as TIC }\end{array}$ & 100 & 100 & 100 & 100 & 100 & 92,7 \\
\hline & & $\begin{array}{l}\text { Falta de apetência dos futuros professores para o uso } \\
\text { das TIC }\end{array}$ & 50 & 50 & 100 & 75 & 70 & 77,3 \\
\hline & & Deficiente currículo de formação & 50 & 100 & 100 & 87,5 & 90 & 92,8 \\
\hline & & $\begin{array}{l}\text { Ausência de materiais e de dispositivos de TIC nas } \\
\text { escolas de estágio }\end{array}$ & 50 & 50 & 50 & 91,6 & 70 & 100 \\
\hline & & Dificuldades de ordem curricular & 50 & 50 & 50 & 79,1 & 40 & 23,7 \\
\hline & & Constrangimentos humano-relacionais & 0 & 0 & 0 & 16,6 & 10 & 14,2 \\
\hline
\end{tabular}

Fonte: Elaboração própria (2019).

Importa agora analisar, com mais pormenor, os constrangimentos invocados no contexto da formação inicial e posteriormente no ensino dos alunos do ensino básico pelos futuros professores.

\subsection{FATORES CONSTRANGEDORES INVOCADOS PARA O USO DAS TIC NA FORMAÇÃO INICIAL}

\subsubsection{Ausência de materiais e/ou constrangimentos técnico-financeiros}

No geral, a ausência de materiais é sentida pelos entrevistados como fator que condiciona uma maior utilização e promoção das tecnologias no contexto da formação inicial muito devido às dificuldades financeiras que as instituições enfrentam para continuar a garantir a aquisição e manutenção de recursos e de equipamentos tecnológicos. São referidas igualmente limitações ao "[...] nível da própria produção de materiais tecnológicos dirigidos ou de suporte à formação", como afirma um docente das didáticas (Pb5.5). Dizem existir um grande número de "[...] episódios de uso das TIC transcritos" (Pb1.5, docente das didáticas) dos quais se servem para apresentar e introduzir atividades com recurso às TIC, mas sentem que são necessários mais exemplos de práticas reais, de maneira que os futuros professores possam visualizar e perceber como é que determinados conteúdos curriculares podem ser trabalhados, "[...] 
porque uma coisa é ouvir ou ler, outra é ver o que é feito na realidade" (Pb5.5, docente das didáticas).

Por outro lado, a acumulação de tarefas/funções desempenhadas, na condição de formadores na instituição, na opinião dos entrevistados, tem-se traduzido inequivocamente num acréscimo substancial de trabalho, impedindo-os, na maioria das vezes, de fazer atualização/formação na área das TIC, ainda que muitas vezes sintam essa necessidade por reconhecerem que dificilmente podem partilhar conhecimentos no uso das tecnologias se não os possuírem. O pouco tempo de que dispõem é muitas vezes "[...] convertido numa burocracia digital pela obrigatoriedade que temos em responder aos e-mails diários" (Pa2.2, presidente do CTC), para além de não lhes permitir fazer um acompanhamento mais próximo da intervenção dos futuros professores na PES/estágio. Os exemplos seguintes ilustram a preocupação manifestada, especialmente pelos supervisores:

\footnotetext{
Sentimos nos últimos anos alguma pressão de vária ordem desde a nossa carga de distribuição docente, o número de horas que temos, ou melhor, que não temos, para acompanhar os estudantes e para fazer qualquer atualização de conhecimentos. (Pa5.6, supervisor).

[...] são poucas as idas ao estágio porque não temos assim tanto tempo, o que está mal, porque permitiria um acompanhamento mais próximo na formação dos nossos estagiários. (Pb11.6, supervisor).
}

À semelhança de outros estudos, os constrangimentos sentidos na esfera dos recursos financeiros, da disponibilidade e acesso ao hardware e software e da falta de tempo útil para fazer formação e/ou acompanhamento dos futuros professores invocados pelos entrevistados têm vindo a ser enunciados por inúmeros autores como barreiras externas que justificam, em grande parte, os elevados níveis de resistência ao uso pedagógico das TIC (BINGIMLAS, 2009; COSTA, 2008; MIRANDA, 2010).

\subsubsection{Deficiente formação dos formadores em TIC}

A insuficiente formação na área das TIC é sentida de forma expressiva pelos entrevistados que desempenham funções de relevo na preparação profissional dos futuros professores como fator impeditivo a um maior uso e promoção das TIC no contexto formativo, nomeadamente pelos supervisores (Quadro 1). Na opinião ilustrativa de um docente das didáticas, "[...] há colegas na instituição para quem as pequenas coisas, como 
ligar o projetor, passar um vídeo ou desligar o computador parece uma aplicação do arco da velha" (Pb5.5), condicionando a forma como os futuros professores vêm e/ou sentem a pertinência do uso das TIC. Como o uso pedagógico de alguns recursos exige um conhecimento específico, nas palavras dos entrevistados é um constrangimento, "[...] principalmente se considerarmos que há defasamento entre alguns docentes que não têm a formação adequada, e que geralmente têm mais idade, e os estudantes que vivem imersos nessas tecnologias" (Pa4.4, docente que integra as TIC).

A falta e/ou pouca formação na área das TIC sentida emerge como um aspecto relevante ao qual as instituições de formação inicial não devem ficar indiferentes, sendo certo que ninguém ensina o que não sabe. As evidências sustentam a pertinência da investigação e pouco contradizem os resultados a que chegou Miranda (2010) e Coronado (2013) ao chamarem a atenção para a formação insuficiente dos formadores no e para o uso das TIC como fator limitativo na preparação profissional dos futuros professores.

Ainda no que se refere à insuficiente formação para o uso pedagógico das tecnologias, mas dos cooperantes, os entrevistados consideram-na também um fator constrangedor com implicações na forma como os futuros professores vêm/sentem o uso das TIC na PES/estágio. Creem ser natural que os cooperantes com mais experiência não usem as TIC como o desejado por não terem tido formação ajustada às reais necessidades vivenciadas, o que reforça os resultados a que chegaram alguns estudos visitados (COSTA et al., 2008; ENOCHSSON; RIZZA, 2009; GEPE, 2010). Para os entrevistados, ainda que a grande maioria dos cooperantes tenha feito a formação em TIC promovida pelo Ministério da Educação quando da distribuição dos computadores Magalhães, "[...] não foram muitos os que foram capazes de explorar esse recurso para potenciar aprendizagens escolares inovadores, por falta de formação adequada" (Pb10.6, supervisor). Como justificação, alegam que a formação ministrada foi majoritariamente de cariz tecnicista e, salvo raras exceções, realizada por formadores com conhecimentos técnicos, mas com poucas competências na área da pedagogia, acabando por privilegiar os aspectos técnicos do uso dos diferentes recursos/programas sem que os mesmos fossem articulados com a didática.

Argumentam, nomeadamente os supervisores, que nem sempre os futuros professores têm oportunidade de observar práticas de uso pedagógico das TIC pelos cooperantes e que os modelos que acabam por ser expostos aos olhos dos futuros 
professores nem sempre corroboram o que é transmitido empiricamente pelos formadores na(s) instituição(ões). As declarações seguintes são ilustrativas:

[...] muitos dos cooperantes utilizam as tecnologias empiricamente utilizando o senso comum e da forma como acham que será a melhor maneira de as usar. (Pa6.5, docente das didáticas).

Nas escolas, muitas das crianças usam os computadores para aceder aos jogos e não os utilizam como recurso para evoluir na aprendizagem devido à utilização pouco inovadora que os cooperantes fazem desses recursos. O problema é que os nossos estagiários vêm esses modelos e tomam-nos como exemplo no terreno. (Pb10.6, supervisor).

\subsubsection{Diferentes concepções/representações dos formadores sobre as TIC}

As diferentes concepções e/ou representações que os formadores, especialmente os cooperantes, manifestam possuir sobre as potencialidades dos recursos tecnológicos parece ser outro dos constrangimentos invocados que condicionam a promoção do uso das TIC na formação inicial, havendo uma grande convergência de opinião entre as categorias de entrevistados (Quadro 1). A maioria dos entrevistados acredita que "[...] muitos são os professores que não utilizam as tecnologias na sua prática pedagógica devido às representações antiquadas que têm do papel do professor no ensino" (Pb11.6, supervisor). Argumentam que os alunos sabem mais hoje sobre as tecnologias que muitos dos seus professores, e isso "[...] assusta-os porque estão convencidos de que têm de ser eles a dizer coisas novas aos alunos e nunca o contrário" (Pb2.2, presidente do $\mathrm{CTC}$ ), fazendo emergir a ideia de que acreditam na crença do professor como detentor do saber.

É certo que o uso das TIC cria alguma insegurança nos formadores por sentirem que há uma tecnologia que interage com a sua função e deixam de poder controlar e/ou monopolizar o que acontece em contexto de sala de aula. Essa forma de sentir contribui, invariavelmente, para um menor uso das tecnologias no contexto de ensino pelos formadores, incluindo o cooperante, e o futuro professor fica impossibilitado de poder observar a sua utilização. Os receios e as crenças que os formadores manifestam sobre as potencialidades e o papel que o professor desempenha na sala de aula, na opinião dos entrevistados, constrangem e influenciam diretamente o uso futuro das TIC pelos futuros professores. 
Outra das razões apontadas pelos entrevistados é a ideia de que existe uma ausência de congruência no uso das TIC entre todos os formadores (das TIC/didáticas/supervisores) que necessita de ser ultrapassada para que os futuros professores possam sentir que os formadores falam a uma só voz no que se refere à promoção do uso pedagógico das tecnologias. Nas palavras ilustrativas de um docente de TIC, "[...] não são apenas as cadeiras das tecnologias que vão mudar a forma como os futuros professores vão olhar para as TIC e fazer com que as utilizem com maior regularidade" (Pb4.3). É igualmente necessário sensibilizar/mobilizar todo o corpo docente da(s) instituição(ões) para o seu uso, nomeadamente os supervisores, não só pela influência que exercem no acompanhamento e orientação das práticas educativas, mas porque são eles que muitas vezes lecionam as UC das metodologias e das didáticas. No que ao discurso oral diz respeito, a opinião manifestada pelos entrevistados é convergente com a de autores como Martinez, Leite e Monteiro (2015), Miranda (2007), Ponte e Serrazina (1998), entre outros.

A opinião de alguns dos entrevistados que lecionam as UC das didáticas confirma, de certa forma, o sentimento expresso anteriormente pelos entrevistados que lecionam as TIC ao cometerem para as UC de TIC a preocupação direta de (exclusivamente) explorarem a perspectiva da utilização educativa das TIC com os futuros professores. As palavras de um docente das didáticas são ilustrativas ao afirmar: "[...] não é diretamente pela minha intervenção que os estudantes utilizam as tecnologias, é mais pela intervenção dos colegas das TIC que desenvolvem mais esse trabalho ao nível pedagógico" (Pb6.5). O discurso proferido leva-nos a inferir sobre a existência de docentes que delegam aos formadores das TIC a competência de formar os futuros professores para o uso pedagógico das TIC no ensino, apresentando-se como fator constrangedor. A par da formação, também o critério de avaliar as competências de uso das tecnologias manifestadas pelos futuros professores é, muitas vezes, nas palavras dos entrevistados, delegado aos formadores que lecionam as TIC, como depreendemos do discurso seguinte:

Não é minha função como supervisor avaliar as competências que os estudantes desenvolveram para usar as tecnologias no processo de ensino, isso é uma competência que não me está atribuída porque existe um grupo de colegas das TIC que tem essa incumbência. (Pb10.6, supervisor).

Educação \& Formação, Fortaleza, v. 4, n. 11, p. 3-23 maio/ago. 2019 
A ausência de diretrizes claras sobre o que avaliar e quem avalia as competências no uso das TIC dos futuros professores cria, no nosso entendimento, um constrangimento a uma maior promoção do uso das TIC na formação inicial com implicações no perfil de saída do professor formado.

A pouca abertura/receptividade de alguns cooperantes para o uso das TIC e a pouca motivação manifestada para as experimentar na sua prática pedagógica são igualmente invocadas como fatores que impedem a observação de práticas de uso das TIC na PES/estágio pelos futuros professores, sendo que muitas das vezes "[...] também Ihes é vedada a oportunidade de poderem experimentá-las no estágio" (Pb10.6, supervisor).

\subsubsection{Falta de apetência dos futuros professores para o uso das TIC}

A falta de apetência manifestada pelos futuros professores é, na opinião dos entrevistados, nomeadamente os supervisores, justificada pela pouca motivação e uma certa resistência para experimentar as TIC na sua prática educativa pela dificuldade que manifestam em encontrar "um fio condutor, um leitmotiv" (Pb11.6, supervisor) que articule interdisciplinarmente os vários conteúdos disciplinares.

Expressam que muitos dos futuros professores possuem uma representação retrógrada do papel do professor no ensino por terem a ideia de que a aula deve ser centrada neles como professores, para assim conseguirem ter um maior controle do que acontece em contexto de sala de aula. Referem que os futuros professores acreditam no mito de que "[...] os alunos têm que estar sempre a olhar para eles enquanto estão a falar e esse desejo é semelhante ao querermos a Lua" (Pb11.6, supervisor), não reconhecendo, por isso, que a noção de controle é falsa.

Para além das representações, na opinião dos entrevistados, os futuros professores manifestam algumas inseguranças/medos no uso das TIC que condicionam a sua vontade em querer experimentá-las, sobretudo nos momentos em que estão a ser observados e avaliados pelo professor supervisor. Nesses momentos, os futuros professores questionam-se sobre "[...] como é que lidam com os seus alunos, como é que dão e tiram a palavra, impõem a ordem na sala de aula, sendo estes os grandes problemas que enfrentam desde logo nos estágios" (Pb3.3, docente de TIC). A insegurança e o medo aumentam se usarem as TIC no desenvolvimento das suas

Educação \& Formação, Fortaleza, v. 4, n. 11, p. 3-23 maio/ago. 2019

DOI: https://doi.org/10.25053/redufor.v4i11.254

http://seer.uece.br/redufor 
atividades letivas, até "porque receiam que o seu fraco desempenho na utilização das tecnologias se traduza numa nota inferior àquela que ambicionam" ( $\mathrm{Pb} 4.3$, docente de TIC), levando-os a não querer experimentá-las.

No geral, observamos que o discurso dos entrevistados acerca da influência das crenças no ensino, o papel do professor na sala de aula e as potencialidades das TIC são convergentes com o referido por autores como Boza, Tirado e Guzmán-Franco (2010), Coronado (2013), Miranda (2010), Morueta e Gómez (2014), Solis (2015), entre outros, atuando como obstáculo à experimentação e desenvolvimento de práticas de uso pedagógico das TIC.

\subsubsection{Deficiente currículo de formação para o uso das TIC}

Os constrangimentos sentidos no âmbito do currículo de formação são igualmente invocados como fatores que limitam uma promoção do uso das tecnologias na formação inicial, merecendo grande consenso entre os entrevistados (Quadro 1). Acreditam que a reestruturação curricular dos planos de estudo dos cursos que habilitam para a docência, feita de acordo com as recomendações de Bolonha, é um espartilho legal no que respeita à organização das áreas curriculares. No seu entender, a necessidade de obedecer ao número fixo de créditos, de acordo com o Sistema Europeu de Transferência de Créditos Acadêmicos (ECTS) nas áreas científicas, retira créditos (tempo) às ciências da educação, incluindo as TIC, sendo, por isso, difícil contemplá-las com o tempo desejado e, como disciplina autônoma, nos planos de estudo dos cursos que formam para a docência. Consideram que a formação encontra-se mais compartimentada e as tecnologias não têm o peso que deveriam ter na formação inicial de professores pelo fato de serem ignoradas no âmbito da legislação. As declarações seguintes são ilustrativas:

\footnotetext{
Conseguimos introduzir as TIC no nosso plano de estudos pós-Bolonha com dificuldade porque é um espartilho legal [...]. (Pb7.6, supervisor).

Agora a legislação para elaborar os planos de estudo Pós-Bolonha é muito apertada e os ECTS nas áreas científicas são tão grandes que até tivemos que pôr disfarçadamente as TIC. (Pa2.5, docente das didáticas).

Bolonha não prevê as tecnologias como área a privilegiar e é perfeitamente possível construir um curso de Bolonha e não haver uma cadeira de tecnologias no currículo todo. (Pb4.4, docente que integra as TIC).
}

Educação \& Formação, Fortaleza, v. 4, n. 11, p. 3-23 maio/ago. 2019 
Para além do constrangimento sentido na introdução das TIC no plano curricular, os entrevistados, nomeadamente os supervisores, sentem que o atual modelo de formação inicial de Bolonha desintegra os estágios da formação, dificultando o uso das tecnologias em contexto de PES/estágio. Sentem que houve uma reversão/retrocesso no que diz respeito à formação inicial de professores, afirmando que, "[...] antes de Bolonha, os estágios eram integrados desde o primeiro ano de formação e os estudantes estagiavam desde logo no contexto de sala de aula com turmas do primeiro ao quarto ano de escolaridade" (Pa9.6, supervisor).

Os futuros professores tinham formação científica, técnica, pedagógica e formação prática de modo articulado e distribuído pelos anos do curso de formação. Atualmente as instituições passaram para um modelo organizativo de formação sequencial no qual inicialmente os futuros professores têm formação científica e só depois têm a formação pedagógica. Na opinião dos entrevistados, o fato de o período de imersão na prática em escolas do ensino básico ser relegado para o curso de mestrado é invocado como um constrangimento no uso/promoção das TIC na preparação dos futuros professores. Acresce a desvantagem de 0 trabalho prático dos futuros professores ser "[...] interrompido semanalmente porque só têm três dias de estágio por semana em contexto de sala de aula e os outros dois são de frequência obrigatória na instituição" (Pb8.6, supervisor). A situação leva a que os futuros professores tenham dificuldade em realizar um trabalho contínuo e sistemático nos estágios. O sentimento expresso pelos entrevistados é o de que "[...] foram forçados a retroceder na qualidade da formação ministrada" (Pb11.6, supervisor).

Ainda no plano dos fatores constrangedores reconhecidos, os entrevistados acreditam na necessidade de existir uma reflexão sobre a atualização dos programas das UC de TIC, de modo que a formação possa acompanhar a evolução daquelas que são as reais necessidades na área do uso pedagógico das tecnologias, por considerarem que os estudantes não ingressam na instituição desprovidos de conhecimentos técnicos na utilização das tecnologias. Acreditam ser fundamental integrar como conteúdos cada vez mais a reflexão sobre o uso das TIC no contexto curricular e profissional, o papel das redes sociais, a segurança e a privacidade, contrariamente à abordagem do domínio técnico e/ou instrumental das tecnologias, que ainda prevalece com relativa frequência nos programas das UC de TIC. 
O reconhecimento de não ser frequente os formadores que lecionam as TIC integrarem sistematicamente as equipes de supervisão condiciona, em certa medida, na opinião dos entrevistados, a promoção e o apoio mais direto no desenvolvimento/ experimentação de práticas com recurso às TIC no processo de ensino e de aprendizagem pelos futuros professores no contexto de PES/estágio. Nas palavras de um docente de TIC, "[...] faz falta uma maior intervenção dos professores das tecnologias nos estágios, porque isso contribuiria para que houvesse mais estudantes a utilizar as tecnologias no contexto de ensino e de aprendizagem" (Pb3.3, docente de TIC).

A dificuldade em garantir que todos os futuros professores "[...] passem pela experiência de colocar em prática os projetos desenvolvidos nas disciplinas de TIC e de observar exemplos de uso pedagógico das tecnologias pelos formadores" (Pb3.3, docente de TIC), cooperantes ou da instituição, é igualmente sentida como limitação no discurso dos entrevistados.

O fato de não se encontrar explícita na grelha de avaliação a obrigatoriedade de avaliar o uso das TIC pelos futuros professores, na opinião dos entrevistados, nomeadamente os supervisores, é igualmente invocado como um constrangimento à promoção de práticas com recurso às TIC no contexto formativo. Para os entrevistados, esse deveria ser um dos requisitos importantes a ter em conta quando se faz a avaliação do desempenho dos futuros professores, mas "[...] não está explícito na grelha que devemos valorizar ou ter em conta as competências que os estagiários revelaram ou desenvolveram para integrar as tecnologias no ensino" (Pb10.6, supervisor), deixando ao critério dos formadores valorizar ou não tais competências.

Atentemos agora sobre os fatores invocados que condicionam o uso e promoção das TIC no ensino dos alunos do ensino básico pelos futuros professores.

\subsubsection{Fatores constrangedores invocados para o uso das TIC no ensino pelos futuros professores}

No que se refere aos constrangimentos percebidos no uso das TIC, mas no contexto do ensino dos alunos do ensino básico, pelos futuros professores, no geral, os entrevistados invocam a ausência de materiais e dispositivos TIC nas escolas de

Educação \& Formação, Fortaleza, v. 4, n. 11, p. 3-23 maio/ago. 2019

DOI: https://doi.org/10.25053/redufor.v4i11.254

http://seer.uece.br/redufor 
PES/estágio, dificuldades de ordem curricular e constrangimentos humanos e/ou relacionais.

Relativamente às dificuldades referentes aos recursos (in)disponíveis que os futuros professores encontram nas escolas de PES/estágio, os entrevistados alegam a ausência de materiais e de dispositivos de TIC, a exemplo de computadores, recursos digitais, multimédia e/ou internet, como condicionante ao desenvolvimento de uma prática de ensino que inclua as TIC como recurso. A falta de equipes técnicas que tenham como função apoiar os docentes na utilização dos recursos tecnológicos bem como efetuar a manutenção/reparação dos mesmos é igualmente um fator que, na opinião dos entrevistados, nomeadamente os supervisores, concorre para uma menor utilização das TIC, não só pelos futuros professores, mas também pelos cooperantes. Alegam ainda que são poucas as escolas de PES/estágio em que os futuros professores têm a possibilidade de usar os diferentes dispositivos/recursos tecnológicos que são abordados na(s) instituição(ões) de formação, salientando o pouco investimento na área das tecnologias por parte do Ministério da Educação na última década. $O$ fato de os alunos do ensino básico terem deixado de ter acesso (fácil) aos computadores Magalhães é igualmente invocado como constrangimento, uma vez que "[...] eram um recurso extra a que os estudantes poderiam recorrer para suprir a falta de recursos existentes nas próprias salas das escolas de estágio" (Pb10.6, supervisor).

Como dificuldades de ordem curricular, invocam a dificuldade sentida pelos futuros professores na gestão do currículo do $1^{\circ}$ ciclo e do ambiente de sala de aula, especialmente no que se refere à distribuição dos conteúdos curriculares a trabalhar pelos respectivos tempos letivos, como limite ao uso das TIC. Na opinião dos entrevistados, muitos dos futuros professores têm dificuldades "[...] em fazer passar a mensagem curricular porque não conseguem cultivar o silêncio e a concentração dos seus alunos na sala de aula" (Pb1.1, diretor). Por sua vez, essa dificuldade "[...] condiciona o uso das tecnologias porque são mais um fator desestabilizador que os impede (aos futuros professores) de serem bem-sucedidos na gestão do ambiente de sala de aula" (Pb11.6, supervisor).

A obrigatoriedade que os professores cooperantes sentem em preparar a turma para as provas finais e a importância que é dada ao preenchimento dos manuais adotados são situações que, segundo os entrevistados, condicionam o tipo de atividades 
que os futuros professores desenvolvem em contexto de sala de aula e que impedem a experimentação das TIC no seu ensino. A afirmação de Pa8.7 (supervisor) é ilustrativa quando declara: "[...] as minhas estagiárias não puderam usar alguns recursos TIC no estágio porque é ordem do agrupamento que seja dado o que está no manual adotado e seguida aquela metodologia de maneira a preparar os alunos para os exames".

Os constrangimentos humanos e/ou relacionais são invocados, ainda que a expressividade seja relativa, como justificação para o (pouco) uso das TIC no ensino pelos futuros professores. São de opinião que o uso priviliegiado das tecnologias em detrimento do lápis e do papel pode dificultar o "[...] desenvolvimento da motricidade fina nos alunos em início de escolaridade, especialmente quando é usado, em exclusividade, o computador na aprendizagem da escrita" (Pa8.6, supervisor). Creem igualmente que o uso de algumas das potencialidades das TIC no ensino dos alunos mais novos, nomeadamente o fórum e o Skype, "[...] inibe o aluno mais tímido a uma maior participação no seu processo de aprendizagem muito pela exposição a que está sujeito perante o outro" (Pa8.6, supervisor), o que, por sua vez, impede o desenvolvimento da relação humana direta (cara a cara) e mais estreita.

\section{CONSIDERAÇÕES FINAIS}

Genericamente os resultados confirmam grande parte dos resultados que a investigação feita com professores, e formadores, vem reconhecendo, designadamente: i) a formação/conhecimentos insuficientes dos formadores na área das TIC, sendo que os saberes e competências nesse domínio são, em larga medida, decorrentes da autoaprendizagem; ii) a ausência de materiais e de dispositivos tecnológicos suficientes; e a iii) fragilidade dos objetivos dos formadores quanto à exigência de formar os futuros professores para o uso pedagógico das TIC.

Contudo, a investigação põe em evidência novas dimensões, sobre as quais interessa refletir, nomeadamente: i) a ausência de uma visão estratégica generalizada e comum a todos os formadores, no sentido de incluir as TIC como conteúdo curricular e estratégia que concebe as TIC como um recurso facilitador do ensino e da aprendizagem dos alunos; ii) uma consciência dos condicionalismos impostos pelos contextos de exercício formativo que os próprios formadores sentem, debatendo diariamente sobre 
aspectos atinentes à carga horária, gestão do currículo, materiais disponíveis, entre outros, que pouco tempo deixam para preparar aulas mais inovadoras, construir materiais, acompanhar a PES/estágio, tecer reflexões, etc.); iii) uma consciência dos bloqueios manifestos pela cultura dominante sobre as potencialidades das TIC na aprendizagem, que atuam como barreiras ao seu uso e promoção.

Os resultados apontam, desse modo, para a dificuldade de os futuros professores passarem pela experiência de observar e experimentar exemplos de uso pedagógico das TIC durante a sua formação.

Ainda que o estudo seja limitado a duas instituições do ensino superior que formam professores e os resultados devam ser interpretados com alguma prudência, não significa que, em face de uma investigação homóloga, não possamos encontrar interpretações muito similares ou muito próximas das registradas. Diante dos resultados alcançados, assinalam-se algumas recomendações que podem ser tomadas de imediato: i) (re)definir o currículo de formação e respectivos programas das UC dos cursos que habilitam para a docência no $1^{\circ} \mathrm{CEB}$, de modo que as TIC possam ser concebidas como conteúdo curricular, sobretudo o seu uso pedagógico; ii) (re)ver os critérios de avaliação/classificação de desempenho do futuro professor na PES/estágio, bem como nas diferentes UC, criando um item específico relativo à utilização das TIC no ensino; iii) sensibilizar os formadores, especialmente os supervisores, para a importância e pertinência de desenvolverem estratégias comuns e concertadas no que à importância e uso das TIC dizem respeito, na preparação profissional dos futuros professores; assim como iv) garantir a oportunidade de o futuro professor poder observar, refletir e experimentar atividades com as TIC no seu percurso formativo.

Em síntese e retomando a ideia da importância atribuída às práticas isomórficas dos formadores e o papel modelador que desempenham na construção do ser professor, as evidências ressalvam igualmente a necessidade de um maior investimento na formação e capacitação dos formadores no e para o uso pedagógico das TIC por se acreditar que a (falta) de formação/conhecimentos na área e as concepções e atitudes que detêm (sobre o ensino, as potencialidades das TIC, etc.) atuam como barreiras à preparação profissional dos futuros professores para o uso das TIC e tendem a influenciar não apenas as práticas, mas também o pensamento dos profissionais que formam.

Educação \& Formação, Fortaleza, v. 4, n. 11, p. 3-23 maio/ago. 2019 


\section{REFERÊNCIAS}

AMADO, J. (Coord.). Manual de investigação qualitativa em educação. Coimbra: Universidade de Coimbra, 2013.

BARDIN, L. Análise de conteúdo. Lisboa: Setenta, 2002.

BINGIMLAS, K. Barriers to the successful integration of ICT in the teaching and learning environments: A review of the literature. Eurasia Journal of Mathematics, Science \& Technology Education, v. 5, n. 3, p. 235-245, 2009.

BOZA, Á.; TIRADO, R.; GUZMÁN-FRANCO, M.-D. Creencias del profesorado sobre el significado de la tecnología en la enseñanza: influencia para su inserción en los centros docentes andaluces. Relieve, v. 16, n. 1, p. 1-14, 2010.

CORONADO, P. Competencias y uso de las TIC por parte de los docentes: un análisis desde las principales Instituciones de Educación Superior (IES) formadoras de formadores en la República Dominicana (2009-2011). 2013. 320 f. Tese (Doctorado en Didáctica y Organización Escolar) - Programa de Posgrado en Didáctica y Organización Escolar, Universidad de Murcia, Murcia, 2013.

COSTA, F. A utilização das TIC em contexto educativo: representações e práticas de professores. 2008. 614 f. Tese (Doutorado em Educação) - Programa de Pós-Graduação em Educação, Universidade de Lisboa, Lisboa, 2008.

COSTA, F. et al. Competências TIC: estudo de implementação. Lisboa: Ministério da Educação, 2008.

COUTINHO, C. Tecnologias Web 2.0 na sala de aula: três propostas de futuros professores de Português. Educação, Formação e Tecnologia, Braga, v. 2, n. 1, p. 75-86, 2009.

ENOCHSSON, A.-B.; RIZZA, C. ICT in Initial Teacher Training: Research review. OECD Education Working Papers, v. 4, n. 38, p. 656-667, 2009.

ESTÉVEZ-NENNINGER, E. et al. Creencias sobre enseñanza y aprendizaje en docentes universitarios. Revista Internacional de Investigación en Educación, Bogotá, v. 6, n. 13, p. 49-64, 2014.

FONSECA, G. As tecnologias de informação e comunicação na formação inicial de professores do $1^{\circ}$ ciclo do ensino básico: crenças e perspectivas de formadores. 2018. 387 f. Tese (Doutorado em Educação) - Programa de Pós-Graduação em Educação, Universidade de Lisboa, Lisboa, 2018.

GEPE. Inquérito aos professores sobre a utilização do Magalhães (2009/2010). Lisboa: Ministério da Educação, 2010.

Educação \& Formação, Fortaleza, v. 4, n. 11, p. 3-23 maio/ago. 2019

DOI: https://doi.org/10.25053/redufor.v4i11.254

http://seer.uece.br/redufor 
MARTINEZ, R.; LEITE, C.; MONTEIRO, A. Os desafios das TIC para a formação inicial de professores: uma análise de agenda internacional e suas influências nas políticas portuguesas. Revista Crítica Educativa, Sorocaba, v. 1, n. 1, p. 21-40, 2015.

MESQUITA, E.; FORMOSINHO, J.; MACHADO, J. Supervisão da prática pedagógica e colegialidade docente. A perspectiva dos candidatos a professores. Revista Portuguesa de Investigação Educacional, Porto, n. 12, p. 59-77, 2012.

MIRANDA, G. Limites e possibilidades das TIC na educação. Sísifo, Lisboa, n. 3, p. 4150, 2007.

MIRANDA, J. Creencias sobre el rol de las tecnologías de información y comunicación en la formación inicial de docentes: explorando las diferencias entre estudiantes y docentes universitarios. 2010. 469 f. Tese (Doctorado en Didáctica y Organización Educativa) - Programa de Posgrado en Didáctica y Organización Educativa, Universidad de Barcelona, Barcelona, 2010.

MORUETA, R.; GÓMEZ, I. Influencias de las creencias del profesorado sobre el uso de la tecnología en el aula. Revista de Educación, Madrid, n. 363, p. 230-255, 2014.

PERALTA, H.; COSTA, F. Competência e confiança dos professores no uso das TIC. Sísifo, Lisboa, n. 3, p. 77-86, 2007.

PONTE, J. P. Estudos de caso em educação matemática. Bolema, Rio Claro, v. 19, n. 25, p. 105-132, 2006.

PONTE, J. P.; SERRAZINA, L. As novas tecnologias na formação inicial de professores. Lisboa: Ministério da Educação, 1998.

SOLIS, C. Creencias sobre enseñanza y aprendizaje en docentes universitarios: revisión de algunos estudios. Propósitos y Representaciones, v. 3, n. 2, p. 227-260, 2015.

TARDIF, M. Saberes docentes e formação profissional. 12. ed. Petrópolis: Vozes, 2011.

TEO, T. et al. Beliefs about teaching and uses of technology among pre-service teacher's. Asia-Pacific Journal of Teacher Education, Lima, n. 36, v. 29, p. 163-174, 2008.

Maria Gorete Ramos Fonseca (Portugal, Lisboa) - Instituto de Educação da Universidade de

Doutora em Educação pelo Uidef.

Lisboa (Uidef)

E-mail: <prof.goretefonseca@gmail.com>.

Recebido em 24 de agosto de 2018.

Aceito em 28 de fevereiro de 2019.

Educação \& Formação, Fortaleza, v. 4, n. 11, p. 3-23 maio/ago. 2019

DOI: https://doi.org/10.25053/redufor.v4i11.254

http://seer.uece.br/redufor 